\title{
Um rico olhar para a amamentação e políticas para a infância no Brasil da virada dos séculos XIX para o XX. A atuação de Fernandes Figueira e outros pioneiros
}

\author{
An inspirational approach to breastfeeding and policies for \\ childhood in Brazil at the turn of the 19th to the 20th century: \\ the work of Dr. Antônio Fernandes Figueira and other pioneers \\ Una perspectiva valiosa para la lactancia materna y las políticas \\ dirigidas a la infancia en Brasil desde finales del siglo XIX al XX: \\ la actuación de Fernandes Figueira y otros pioneros
}

\begin{abstract}
AMAMENTAÇÃO E POLITICAS PARA A INFÂNCIA NO BRASIL: A ATUAÇÃO DE FERNANDES FIGUEIRA, 1902-1928. Sanglard G, organizadora. Rio de Janeiro: Editora Fiocruz; 2016. 324 p. ISBN 978-85-7541-485-9
\end{abstract}

doi: $10.1590 / 0102-311 \times 00224717$

A historiadora Gisele Sanglard nos apresenta, nesta obra, interessante panorama das visões e iniciativas no campo da assistência à infância, pelas primeiras gerações de médicos e serviços de saúde dedicados à puericultura e pediatria, então nascente como especialidade médica, no Rio de Janeiro e Salvador (Bahia), no final do século XIX e primeiras décadas do século XX.

Os seis capítulos que compõem a publicação apresentam, como fio condutor, as ações de homens que, além de praticar a medicina de crianças, em faculdades de medicina e instituições filantrópicas, as Santas Casas de Misericórdia, atuaram como verdadeiros ativistas da causa da infância, de uma forma geral, e em particular da promoção do aleitamento materno, junto à sociedade e aos governos da época, inclusive formulando e implementando políticas "públicas" neste campo.
A obra mostra como a atuação destes primeiros pediatras, como Fernandes Figueira (personagem central de análise nesta obra) e Moncorvo Filho, no Rio de Janeiro, e Martagão Gesteira, em Salvador, embasados pelos crescentes conhecimentos científicos da microbiologia de Pasteur e de muitos outros ramos da ciência, vão revestir de cientificidade uma "puericultura" que anteriormente se resumia a conselhos veiculados por médicos famosos baseados em suas práticas e vivências assistenciais 1 .

O livro, portanto, constitui obra de referência para estudiosos das políticas públicas para a infância e, em particular, das voltadas para atenção à saúde da criança e de promoção do aleitamento materno, mas também da história da saúde pública nacional, de forma mais geral. Muita atenção certamente vai provocar entre aqueles interessados na evolução dos conhecimentos científicos da pediatria e da nutrição infantil, em especial do aleitamento materno.

O historiador Renato Franco, no prefácio do livro, salienta a inovação metodológica trazida por Philippe Ariès (1914-1984) na forma de compreender a infância, de considerar os aspectos econômicos e sociais e, fundamentalmente, a temporalidade que marcavam os sentimentos de infância e de família na sociedade 2 . Desse ponto de vista, a obra deixa claro como a intervenção 
dos pediatras, associados a filantropos e juristas, teve como contexto a conjuntura pós-Abolição da Escravidão (1888) e Proclamação da República (1889), marcada pela então chamada "questão social", ou seja, pobreza urbana e males decorrentes da industrialização, para as famílias e, em especial, mulheres operárias e suas crianças. Dentro dessa preocupação, insere-se a necessidade de superação do então denominado "problema da infância”, como demonstração de uma "nova era do país, liberta de arcaísmos e pronta para o futuro”. Compondo o "problema da infância", situações como a absurdamente alta mortalidade infantil e a questão do abandono de recém-nascidos, com questionamento da antiquíssima prática da "roda dos enjeitados”, que desde o século XVIII era tida como solução para salvá-los e que passa então a ser vista como matadouro de crianças. A taxa de mortalidade infantil (TMI) atingiria, no Rio de Janeiro, 213 óbitos no primeiro ano de vida, para cada mil nascidos vivos. Como termos de comparação, no Brasil, em 2015, a TMI chegou a 15 , contudo muitos países europeus, Japão, Cuba etc., já ostentam TMI entre 2 a 43.

O primeiro capítulo, Alimentação na Primeira Infância: Médicos, Imprensa e Aleitamento no Fim do Século XIX, de Karoline Carula, vai surpreender os atuais militantes e estudiosos da promoção do aleitamento materno. Mostra como médicos dessa época, no Rio de Janeiro imperial, usando argumentos científicos, morais e religiosos, já defendiam arduamente o leite materno como melhor alimento para crianças na "primeira infância” (denominação de então para o período entre o nascimento e o desmame e não como hoje, que se conceitua de 0-6 anos). A autora evidencia, mediante fontes históricas primárias, como artigos da imprensa leiga e do jornal A Mãe de Família (publicado por médicos para educar as mulheres a serem "boas mães", em especial para divulgar bons hábitos de alimentação infantil, particularmente amamentação), que esse conhecimento dos médicos estava fortemente conectado com as mais recentes publicações científicas europeias, especialmente da França, então "modelo para os sonhos civilizatórios da camada do- minante brasileira”. Dentre as alternativas à amamentação orientadas, chama a atenção o aleitamento pelas amas de leite, quase sempre escravas negras, agenciadas pelos proprietários, num rentável negócio, o "Aleitamento mercenário".

O segundo capítulo, Fernandes Figueira e a Política de Assistência: Estado, Filantropia e Aleitamento Materno, de Gisele Sanglard, apresenta o pensamento e propostas de Figueira para a assistência à infância no Rio de Janeiro e como as praticou na direção da Policlínica de Crianças da Santa Casa e da Inspetoria de Higiene Infantil, órgão do então recém-criado Departamento Nacional de Saúde Pública, equivalente ao atual Ministério da Saúde.

Já no terceiro capítulo, Salvando o Esteio da Nação: Moncorvo Filho e o Instituto de Proteção e Assistência à Infância (IPAI) do Rio de Janeiro, de Maria Martha de Luna Freire, podemos conhecer as propostas de assistência à infância deste outro grande pioneiro da pediatria e o papel do serviço por ele criado. No IPAI, implantou suas estratégias para enfrentar a mortalidade infantil, em especial a promoção do aleitamento, com palestras e consultas para lactantes, concursos de "robustez infantil" para bebês amamentados etc. $\mathrm{O}$ instituto também realizava exames de amas de leite e o "Gotas de Leite", modelo francês de distribuição de leite de vaca esterilizado, um dos pontos de divergência com Figueira, que criticava a proposta, pelo risco de desestímulo à amamentação, preocupação, aliás, que viria a ser consagrada na atual legislação nacional de proteção do aleitamento materno.

Entre a Assistência e a Higiene: Saúde Pública e Infância no Rio de Janeiro e na Bahia (1921-1933), quarto capítulo, de Luiz Otavio Ferreira e Lidiane Monteiro Ribeiro, trata da atuação de Figueira como dirigente da Inspetoria de Higiene Infantil, na capital federal, e do Serviço de Higiene Infantil Federal da Bahia, dirigido por Martagão Gesteira, pediatra da Faculdade de Medicina da Bahia, também ativista da proteção à infância, como seus congêneres da pediatria carioca.

No quinto capítulo, Embaixadores da Academia: Puericultura, Congressos da Criança e a Reper- 
cussão Multinacional da Medicina Brasileira, Okezi T. Otovo discorre sobre a participação de profissionais brasileiros no diálogo internacional sobre puericultura e proteção à família, especialmente via "Congressos Pan-americanos da Criança", ocorridos após 1916, inclusive com participação do movimento feminista.

Finalmente, o sexto capítulo é a transcrição de Bases Científicas da Alimentação da Criança: suas Consequências Sociais (Carta aberta ao Sr. M.R.G.P), através do qual Figueira explicita as bases de sua política de assistência à infância, salientando a importância da abertura de consultórios de lactantes e câmaras de amamentação, para permitirem às mães operárias amamentarem seus filhos.

O livro também traz um fac-símile da obra de Figueira, o Livro das Mães: Consultas Práticas de Higiene Infantil, que deliciará os leitores com as orientações médicas da época, para perguntas de mães sobre higiene, alimentação e doenças da infância. Também aqui realce é dado para a amamentação, na qual se localizaria "a salvação da criança”.
Paulo Vicente Bonilha Almeida 1,2

1 Secretaria Municipal de Saúde de Campinas, Campinas, Brasil.

2 Faculdade de Ciências Médicas, Universidade Estadual de Campinas, Campinas, Brasil.

paulobonilha@hotmail.com

1. Mendes RT. Trabalho e doutrina: os caminhos da prática pediátrica nos centros de saúde [Tese de Doutorado]. Campinas: Universidade Estadual de Campinas, Faculdade de Ciências Médicas; 1996.

2. Ariès P. A criança e a vida familiar no antigo regime. Lisboa: Relógio d’Água; 1988.

3. United Nations Children's Fund. The State of the World's children 2016. A fair chance for every child. https://www.unicef.org/brazil/pt/ resources_33640.html (acessado em 21/Dez/ 2017). 